\title{
Investigation of Copper and Zinc on the Content in Haizhou Bay and in Platycephalus Indicus
}

\author{
Zhang Bingzhi ${ }^{1,2,3,4 *}$, Li Zeyu ${ }^{2}$ and Chen Yanan $^{3}$ \\ ${ }^{1}$ Jiangsu Key Laboratory of Marine Bioresources and Environment, Huaihai Institute of Technology, China \\ 2Jiangsu Key Laboratory of Marine Biotechnology, Huaihai Institute of Technology, China \\ ${ }^{3}$ Co-Innovation Center of Jiangsu Marine Bio-industry Technology, Huaihai Institute of Technology, China \\ ${ }^{4}$ Jiangsu Marine Resources Development Research Institute, China \\ Submission: April 22, 2019; Published: May 20, 2019
}

Corresponding author: Zhang Bingzhi, Jiangsu Key Laboratory of Marine Bioresources and Environment, Huaihai Institute of Technology, 59 Cangwu Road, Haizhou, Lianyungang, 222005, China

Abstract

The contents of heavy metals copper $(\mathrm{Cu})$ and zinc $(\mathrm{Zn})$ in water, sediment, fish skin and flesh of fish in Haizhou Bay were investigated twice in 2017 and 2018. It was found that the contents of $\mathrm{Cu}$ and $\mathrm{Zn}$ increased year by year. In addition, the contents of $\mathrm{Cu}$ and $\mathrm{Zn}$ in water and sediment decreased with the increase of offshore distance, indicating that the source of importation was terrestrial, which was consistent with the literature reports. Although $\mathrm{Cu}$ and $\mathrm{Zn}$ in water belong to class one of seawater, according to Müller's accumulation index, $\mathrm{Cu}$ in sediments of some sampling sites has been moderately polluted and $\mathrm{Zn}$ has also been slightly polluted. Although the content of $\mathrm{Cu}$ and $\mathrm{Zn}$ in skin and flesh of Platycephalus indicus does not exceed the food standard limit, its higher enrichment coefficient increased with the increase of $\mathrm{Cu}$ and $\mathrm{Zn}$ concentration in water. If the heavy copper and zinc sources imported into Haizhou Bay are not regulated, it may also cause food safety problems for fish.

Keywords: Haizhou Bay; Heavy mental Copper and Zinc; Platycephalus indicus

\section{Introduction}

Haizhou Bay was in the north of Jiangsu Province, China. Beginning in the north of Rizhao Lanshan Town, Shandong

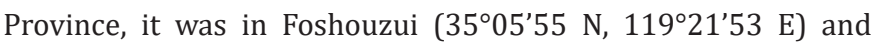
extending south to Gaogong Island, Lianyungang City $\left(34^{\circ} 45^{\prime} 25\right.$ $\mathrm{N}, 119^{\circ} 29^{\prime} 45 \mathrm{E}$ ). It was a trumpet-shaped open bay bordering the Yellow Sea, with a bay mouth width of $42 \mathrm{~km}$ and an area of $876.39 \mathrm{~km}^{2}$. It was an important aquaculture and fishing base in Jiangsu Province and one of the eight major fishing grounds in China [1]. In recent years, with the exploitation of marine resources, the development of coastal cities and industrialization, and the frequent trade between coastal ports, the pollution of the marine environment had become increasingly serious, among which heavy metals were important pollutants with potential dangers. Different from other pollutants, heavy metals were typical inorganic toxic substances. They couldn't be degraded by microorganisms in water. They could only migrate and transform between water, sediment and organisms in different valence states, thus dispersing and enriching. Heavy metals in seawater could be enriched in algae and sediment even if their concentration was very low.

They were harmful to human health through the transmission of food chain and had become persistent organic pollutants [2].
It would have a serious impact on the safety of coastal ecological environment. The available data showed that the content of heavy metals in water phase was small, and the content of heavy metals in sediments was much higher than that in corresponding water phase [3]. $\mathrm{Cu}$ and $\mathrm{Zn}$ were the main factors in marine heavy metal pollution. Through the study of $\mathrm{Cu}$ and $\mathrm{Zn}$, we could understand the pollution status of the whole heavy metal from the side. Therefore, the investigation of $\mathrm{Cu}$ and $\mathrm{Zn}$ in aquatic and sedimentary was helpful to understand the source and distribution of heavy metal pollution and had important environmental warning significance. Flathead fish (Platycephalus indicus) was a kind of offshore bottom fish, which inhabited shallow sea area. It was usually buried in the sediment of the seabed. It moved slowly and does not form large groups. It was an important fresh-eating fish for coastal residents. Its pollution status had a very direct impact on people's health.

\section{Materials and Methods}

\section{Sample Collection and Processing}

In this study, water samples were collected on June 28, 2017 and June 8, 2018, at the peak of the day (shallow silt on the shore, only boat sampling at high tide). Surface water was collected according to the standard of seawater sampling. 
Sample collection points were shown in Figure 1 and distributed in Huizhou Bay, totaling 8 points. After sampled, the content of heavy metals was determined by atomic absorption spectrometry in accordance with Ocean Monitoring Code [4]. The instrument model was Varian AA140/240 of the United States. The methods of sediment collection, pretreatment, preparation, preservation and determination were all in accordance with the requirements of reference 4.

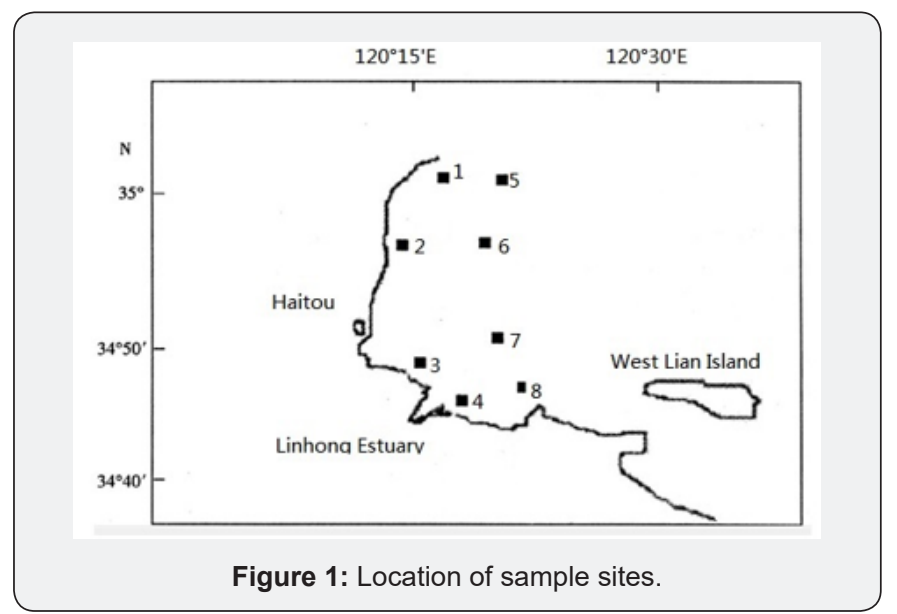

Surface sediment was collected by grab sampler. Surface $0-2 \mathrm{~cm}$ mud samples were collected by plastic spoon without disturbance in the center. The samples were described and recorded on site. Number was put into clean polyethylene bag and stored at $0-4^{\circ} \mathrm{C}$. Samples thawed to room temperature are airdried in a cool and ventilated place in the laboratory [5]. Gravel, shells and sawdust are removed. Agate mortar is used to grind them and pass through 160 mesh sieves. Samples were taken after full mixing for determination and analysis. Flathead fishes were caught in the Haizhou Bay area while sampling. According to the method of literature 5, the $\mathrm{Cu}$ and $\mathrm{Zn}$ in fish skin and meat were determined respectively.

\section{Method of Evaluating Heavy Metal Pollution Level- Geo accumulation Index}

Geo accumulation Index $\left(I_{\text {geo }}\right)$ was a quantitative index for studying heavy metals in sediments proposed by German scientist Muller in 1969 [6]. It could be used to evaluate the pollution degree of heavy metals. The formula is as follows:

$$
I_{\text {geo }}=\log _{2} \frac{C n}{1.5 B n}
$$

In the formula: $\mathrm{Cn}$ was the measured element $\mathrm{n}$ content, $\mathrm{Bn}$ was the geochemical background value of the element, and the element content that was not polluted is generally selected. The industrialization of Haizhou Bay began gradually after 1990. Therefore, the background values of elements in coastal soils of Jiangsu Province were obtained from 1980 to 1981 in literature 7, in which $\mathrm{C}_{\mathrm{Cu}}=15.02 \mathrm{ppm}$ and $\mathrm{C}_{\mathrm{Zn}}=47.15 \mathrm{ppm} . I_{\text {geo }}<0$, no pollution; $0<I_{\text {geo }}<1$, light pollution; $1<I_{\text {geo }}<2$, moderate pollution; $2<I_{\text {geo }}$ $<3$, moderate pollution; $3<\mathrm{I}_{\text {geo }}<4$, heavy pollution; $4<\mathrm{I}_{\text {geo }}<5$, heavy pollution; $\mathrm{I}_{\mathrm{geo}}>5$, serious pollution.

\section{Bioconcentration Factors (BCF)}

Bioconcentration coefficient referred to the ratio of the concentration of an element or compound in an organism to that of the substance in the environment in which it lived [7]. It can express the quantitative relationship between the bioaccumulation, concentration, accumulation, amplification and absorption capacity and the degree. The calculation formula was as follows:

$$
B C F=C b / C w
$$

Among them, Cb was the content of heavy metals in organisms, Cw was the content of heavy metals in water (Figure 1).

\section{Results and Discussion}

\section{Content of $\mathrm{Cu}$ and $\mathrm{Zn}$ in Seawater of Haizhou Bay}

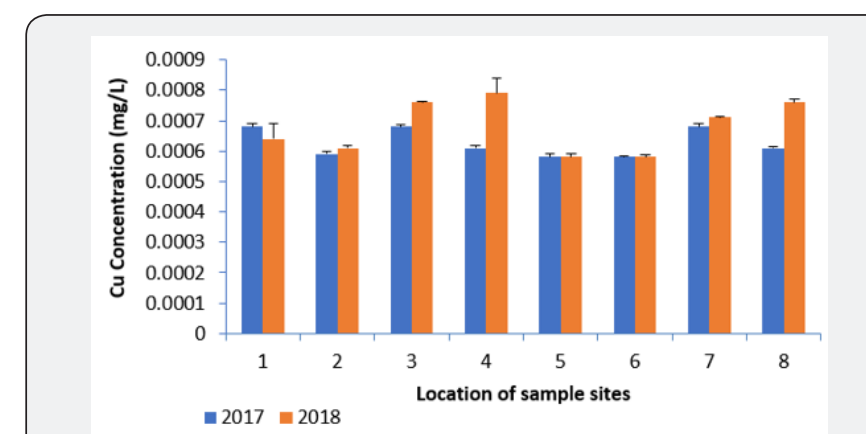

Figure 2: Comparison of $\mathrm{Cu}$ concentration in seawater of Haizhou Bay in 2017 and 2018.

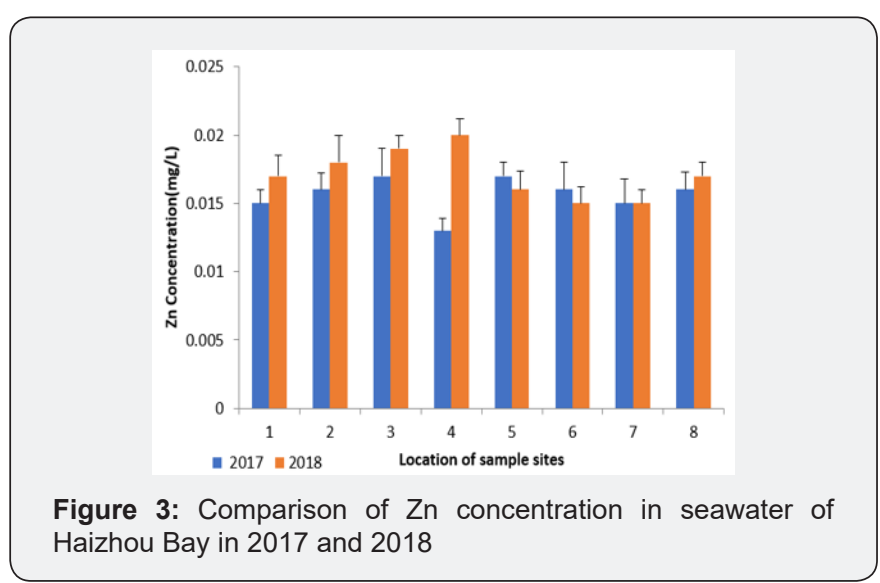

(Figures 2 \& 3) showed that the contents of $\mathrm{Cu}$ and $\mathrm{Zn}$ in sea water in 2018 were higher than those in 2017, which indicated that the contents of heavy metals in sea water in Haizhou Bay were increasing. The closer offshore, the higher the content of heavy metals, which was the same as that reported in literature 8. The reason was that $\mathrm{Cu}$ and $\mathrm{Zn}$ in seawater comed from land input. The relatively high concentration of $\mathrm{Cu}$ and $\mathrm{Zn}$ in sampling points 3 and 4 was related to the topography of Haizhou Bay [8]. Although sampling point 4 was in Linhong estuary, there are tidal gates built on Linhong River, which seldom open, so the area formed a concave shape. It was possible to accumulate higher concentrations of $\mathrm{Cu}$ and $\mathrm{Zn}$ due to the concentration of seawater. 


\section{Pollution Assessment of $\mathrm{Cu}$ and $\mathrm{Zn}$ in Water Samples and Sediments}

Table 1: Cu and Zn geo accumulation index of different location of sample sites in 2017 \& 2018.

\begin{tabular}{|c|c|c|c|c|c|c|c|c|c|}
\hline \multirow{2}{*}{\multicolumn{2}{|c|}{ Item 1}} & \multicolumn{8}{|c|}{ Location of sample sites } \\
\hline & & \multirow{2}{*}{$\begin{array}{c}2 \\
1.38\end{array}$} & \multirow{2}{*}{$\begin{array}{c}3 \\
1.63\end{array}$} & \multirow{2}{*}{$\begin{array}{c}\mathbf{4} \\
1.65\end{array}$} & \multirow{2}{*}{$\begin{array}{c}\mathbf{5} \\
1.38\end{array}$} & \multirow{2}{*}{$\begin{array}{c}6 \\
1.30\end{array}$} & \multirow{2}{*}{$\begin{array}{c}7 \\
0.08\end{array}$} & \multirow{2}{*}{$\begin{array}{c}8 \\
-0.02 \\
\end{array}$} & \\
\hline $\mathrm{Cu}$ of 2017 & 2.28 & & & & & & & & \\
\hline & & 2.26 & 1.40 & 1.65 & 1.71 & 1.39 & 0.29 & 0.14 & 0.09 \\
\hline & & 0.86 & 0.84 & 0.97 & 0.90 & 0.90 & 0.63 & 1.28 & 1.54 \\
\hline & & 3.22 & 0.90 & 1.12 & 1.29 & 0.89 & 0.06 & 2.35 & 2.74 \\
\hline
\end{tabular}

(Table 1) According to literature 8, it was known that $\mathrm{Cu}$ and $\mathrm{Zn}$ in Haizhou Bay were the result of land runoff input and coastal deposition. The geo accumulative index of sediment plots at each sampling point in Table 1 showed that the $\mathrm{Cu}$ and $\mathrm{Zn}$ in the sediments of other sampling points were basically from mild to moderate pollution except sampling point 1 . The results of moderate or even heavy pollution at Sampling Point 1 might be related to the ongoing port construction nearby. Referring to the Water Quality Standard of the People's Republic of China (GB 3097-1997) and the Quality Standard of Marine Sediments of the People's Republic of China (GB 18668-2002), Cu and Zn in seawater belonged to the first class of water and belonged to cleaner water, while the content of copper in most sampling points of sediments was in the second class of standards, and the content of zinc was in the lower position of the first class of standards. The content of $\mathrm{Cu}$ and $\mathrm{Zn}$ in sediments was obviously higher than that in water. The results showed that $\mathrm{Cu}$ and $\mathrm{Zn}$ have high enrichment ability in sediments. Although the slow increase of heavy metals in seawater would not immediately cause a significant decline in seawater quality, it might cause serious pollution of sediments.

\section{Content and Evaluation of $\mathrm{Cu}$ and $\mathrm{Zn}$ in Platycephalus indicus}

Table 2: $\mathrm{Cu}$ and $\mathrm{Zn}$ concentration in flesh and skin of Platycephalus indicus from Haizhou Bay

\begin{tabular}{|c|c|c|c|c|}
\hline \multirow{2}{*}{ Heavy metals } & \multicolumn{2}{|c|}{ Fish skin } & \multicolumn{2}{c|}{ Flesh of fish } \\
\cline { 2 - 5 } & $\mathbf{2 0 1 7}$ & $\mathbf{2 0 1 8}$ & $\mathbf{2 0 1 7}$ & $\mathbf{2 0 1 8}$ \\
\hline $\mathrm{Cu}$ & $0.4469 \pm 0.0009$ & $0.5571 \pm 0.0028$ & $0.3218 \pm 0.082$ & $0.3589 \pm 0.048$ \\
\hline $\mathrm{Zn}$ & $2.482 \pm 0.0166$ & $3.334 \pm 0.0167$ & $1.0468 \pm 0.2974$ & $1.2968 \pm 0.0868$ \\
\hline
\end{tabular}

(Table 2) The results showed that the contents of $\mathrm{Cu}$ and $\mathrm{Zn}$ in the flesh and skin of Platycephalus indicus did not exceed the stipulated values of the National Food Safety Standard (GB27622012), but Table 2 could infer that with the increase of $\mathrm{Cu}$ and $\mathrm{Zn}$ in seawater, the contents of heavy metals in fish meat and skin also increased correspondingly, so we should be vigilant

about the contents of heavy metals in seawater. In addition, the content of $\mathrm{Cu}$ and $\mathrm{Zn}$ in fish skin was higher than that in fish flesh, which indicateed that adsorption had a great influence on the enrichment of organisms. This study was helpful to guide people to pay attention to the hygienic condition of fish skin in their daily diet.

\section{Bioaccumulation of $\mathrm{Cu}$ and $\mathrm{Zn}$ in Meat and Skin of Platycephalus indicus}

Table 3: Cu and Zn BCF in flesh and skin of Platycephalus indicus from Haizhou Bay.

\begin{tabular}{|c|c|c|c|c|}
\hline \multirow{2}{*}{ Heavy metals } & \multicolumn{2}{|c|}{ Fish skin } & \multicolumn{2}{c|}{ Flesh of fish } \\
\cline { 2 - 5 } & $\mathbf{2 0 1 7}$ & $\mathbf{2 0 1 8}$ & $\mathbf{2 0 1 7}$ & $\mathbf{2 0 1 8}$ \\
\hline $\mathrm{Cu}$ & $\mathbf{7 1 4}$ & 826 & 514 & 532 \\
\hline $\mathrm{Zn}$ & 159 & 194 & 67 & 76 \\
\hline
\end{tabular}

(Table 3) According to the calculation of bioaccumulation coefficient of $\mathrm{Cu}$ and $\mathrm{Zn}$ in the meat and skin of Platycephalus indicus, the bioaccumulation ability of copper in Platycephalus indicus was much higher than that of zinc. Enrichment coefficient increased with the increase of concentration in water. Biological enlargement effect on environmental pollutants should be noticed by researchers.

\section{Conclusion}

Like the report in literature 8 , the source of $\mathrm{Cu}$ and $\mathrm{Zn}$ in Haizhou Bay might be caused by land importation, and the monitoring of land-based pollution sources should be controlled. Compared with the data of 2017 and 2018, except for the sample points, the content of $\mathrm{Cu}$ and $\mathrm{Zn}$ was increasing, which indicated that if no further measures are taken, the pollution of heavy metals would be aggravated. The content of $\mathrm{Cu}$ and $\mathrm{Zn}$ in the body of Platycephalus indicus was higher than that in the water sample and sediment, which indicated that the bioaccumulation effect of $\mathrm{Cu}$ and $\mathrm{Zn}$ in Platycephalus indicus was obvious, and the content of $\mathrm{Cu}$ and $\mathrm{Zn}$ in the skin was higher than that in the flesh, which indicated that the skin adsorption effect was greater than the bioaccumulation effect, and had guiding significance for human 
dietary habits. Although the content of $\mathrm{Cu}$ and $\mathrm{Zn}$ in the water did not reach the level of pollution warning, the heavy metals in the sediments of some areas on the surface of the ground accumulated number had reached the level of moderate pollution, and their future harm could not be neglected due to the biological amplification effect.

\section{Acknowledgement}

This research was supported by A Project Funded by the Priority Academic Program Development of Jiangsu Higher Education Institutions, Study on Environmental and Ecological Restoration of Guanhe Estuary (CXKT20180313) and Ecological Effects of Characteristic Pollutants in Typical Seafood in Haizhou Bay (2013HS011).

\section{References}

1. Xu Rong, Xu Rui, Masuhua (1995) Study on pollution in Haizhou Bay by principal component analysis. Marine Environmental Science 14(2): 28-32.

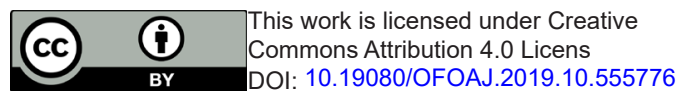

2. Qiao Lei, Yuan Xuyin, Li Amei (2005) Heavy metal characteristics and ecological risk analysis of Jiangsu coastal zone. Journal of Agricultural Environmental Sciences 24: 178-182.

3. Jia Zhenbang, Huo Wenyi (2000) Applying Secondary Phase Enrichment Coefficient to Evaluate Heavy Metal Pollution in Chaihe Sediment. Journal of Peking University 36(6): 808-812.

4. National Oceanic Administration (2007) GB 17378.3-2007 Marine Monitoring Code. In: China Standards Press, Beijing, China, p. 1-8.

5. Liu Danchi, Shao Changming (2007) Determination and distribution of heavy metals in fish. China Testing Technology 33 (4): 121-122.

6. Müller G (v) Index of geoaccumulation in sediments of the Rhine River Geo Journal 2(3): 108-118.

7. Chen Bangben, Hu Rongqin, Chen Mingda (1985) The Natural Background-values of Environmental Elements in the beach Soils of Jiangsu Province. Journal of Nanjing agricultural university 9(3): 5460.

8. Meng Kun, Xu Min, Xu Wenjian, Ding Yanzhe, Zhou Cong (2018) Sources Apportionment and Pollution Assessment of Heavy Metals in the Sediments of the Northern Haizhou Bay in China. Journal of Nanjing normal university (Natural science edition) 41(2): 99-106.

\section{Your next submission with Juniper Publishers will reach you the below assets}

- Quality Editorial service

- Swift Peer Review

- Reprints availability

- E-prints Service

- Manuscript Podcast for convenient understanding

- Global attainment for your research

- Manuscript accessibility in different formats ( Pdf, E-pub, Full Text, Audio)

- Unceasing customer service

Track the below URL for one-step submission https://juniperpublishers.com/online-submission.php 